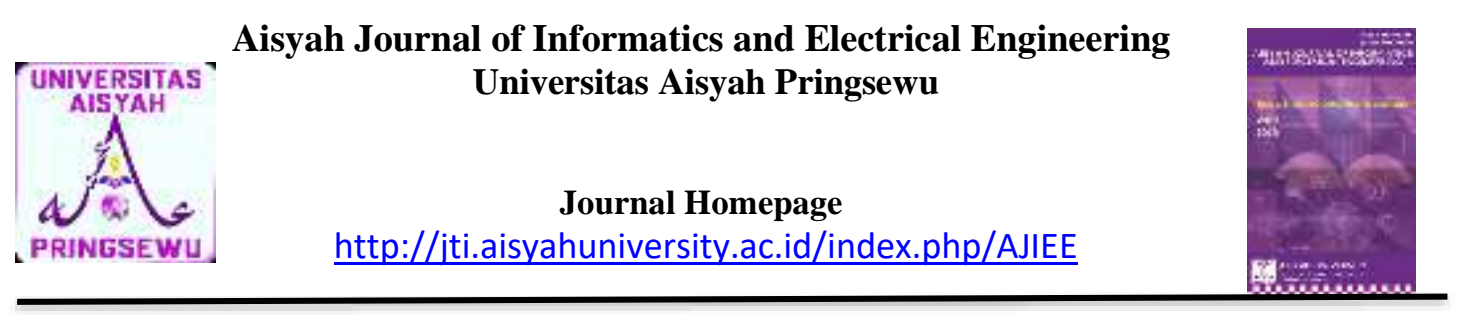

\title{
Sistem Identifikasi Citra Daun Berbasis Segmentasi Dengan Menggunakan Metode K-Means Clustering
}

\author{
Nuari Sivi Anisa ${ }^{1}$, Tahta Herdian Andika ${ }^{2}$, Fitri Hardiyanti ${ }^{3}$ \\ ${ }^{1}$ Program Studi Sistem Informasi, Fakultas Sains dan Teknologi \\ ${ }^{2,3}$ Program Studi Teknik Informatika, Fakultas Teknologi dan Informatika \\ ${ }^{1}$ Universitas Nahdlatul Ulama \\ ${ }^{2}$ Universitas Aisyah Pringsewu \\ e-mail: ${ }^{1}$ nuarianisasivi@gmail.com, ${ }^{2}$ tahta.herdian.a@gmail.com
}

\begin{abstract}
Abstrak
Citra atau gambar berwarna memiliki banyak jenis nilai intensitas pada masing-masing piksel dalam satu citra. Dilihat secara langsung citra seperti memiliki warna yang sama dengan citra yang lain. Namun bila diolah oleh komputer suatu piksel dengan warna yang sama dengan piksel yang lain, ternyata memiliki kombinasi nilai intensitas yang berbeda. Sehingga, perbedaan nilai varietas ini akan mempengaruhi hasil dari pengolahan citra itu sendiri.

Dalam penlitian ini dilakukan uji coba proses Segmentasi citra berwarna pada citra daun. Segmentasi merupakan salah satu bagian penting dalam analisis citra, karena pada prosedur ini gambar/citra yang diinginkan akan dianalisis untuk proses yang lebih lanjut agar lebih mudah di analisis, misalnya pada identifikasi pola.Segmentasi citra dapat membagi menjadi beberapa langkah dalam proses analisis dan mengambil sebagian objek yang diinginkan.Salah satu teknik dalam segmentasi citra adalah dengan clustering. Clustering adalah suatu usaha untuk melakukan pengelompokan data berdasarkan kelas dan merupakan metode mengelompokkan data dalam suatu dataset.Segmentasi citra dan identifikasi pada penelitian ini menggunakan metode K-Means clustering. K-Means merupakan metode yang simple dan cepat perhitungannya, Sebelum melakukan segmentasi atau identifikasi pada daun terlebih dahulu menentukan ruang warna menggunakan CIELab. Identifikasi data test menggunakan dua pendekatan, yaitu analisis bentuk dan analisis tekstur.
\end{abstract}

Kata Kunci : Identifikasi , K-means clustering, Segmentasi Citra 


\section{Pendahuluan}

Perkembangan teknologi pengolahan citra (image processing) sekarang ini menyediakan kemungkinan manusia untuk membuat suatu sistem yang dapat mengenali suatu citra digital. Pengolahan citra merupakan salah satu jenis teknologi untuk menyelesaikan masalah mengenai pemrosesan gambar. Dalam pengolahan citra, gambar diolah sedemikian rupa sehingga gambar tersebut dapat digunakan untuk aplikasi lebih lanjut.

Segmentasi merupakan suatu bagian penting dalam analisis citra, karena pada proses ini gambar/citra yang diinginkan akan dianalisis untuk proses yang lebih lanjut agar lebih mudah di analisis, misalnya pada pengenalan pola.Segmentasi citra yang merupakan bagian dari analisis citra digunakan untuk mengelompokan menjadi beberapa bagian dan mengambil sebagian objek yang diinginkan. Pada bidang pengolahan citra, segmentasi citra mengacu pada proses pembagian citra digital ke dalam multiple region (himpunan piksel). Tujuan akhir dari segmentasi adalah menyederhanakan suatu gambar agar citra/gamabr dapat lebih mudah dianalisis. Salah satu teknik dalam segmentasi citra adalah dengan clustering. Clustering melakukan pengelompokan data berdasarkan masing-masing kelas dan merupakan metode mengelompokkan atau mempartisi data dalam suatu data.Terdapat beberapa metode clustering yang digunakan untuk menyelesaikan permasalahan tentang segmentasi citra antara lain Metode Watershed, metode Chan Vese, algoritma Fuzzy C-Means, PSO (Particle Swarm Optimization), FO-DPSO (Fractional-Order DPSO) DPSO (Darwinian Particle Swarm Optimization) dan K-means clustering.
Terdapat faktor-faktor tertentu dalam segmentasi citra yang memberikan hasil yang kurang memuaskan pada suatu citra tertentu. Hal ini dapat dipengaruhi oleh beberapa faktor yang terdapat pada citra itu sendiri seperti citra yang mengalami degradasi gambar atau citra yang warnanya sudah kabur, pencahayaan dan citra terdapat noise . Dan juga dapat disebabkan oleh metode yang digunakan belum mampu melakukan segmentasi citra dengan baik. Salah satu metode segmentasi citra yang belum mampu atau perlu dikembangkan lagi adalah metode watershed dan metode chan \& vese. Metode watershed merupakan salah satu metode dalam segmentasi citra yang membagi citra menjadi region yang berbeda dengan menggambarkan citra sebagai relief topografi. Metode watershed menghasilkan terlalu banyak region yang menyebabkan bagian penting objek terpisah atau disebut oversegmentasi, sehingga perlu dilakukan pengembangan metode [1]. Fuzzy C-Means merupakan algoritma yang populer digunakan dalam teknik fuzzy clustering. Metode algoritma Fuzzy C-Means untuk segmentasi citra dilakukan dengan menggabungkan beberapa algoritma optimasi atau algoritma metaheuristik seperti genetic algorithm $(G A)[2]$.Sedangkan untuk KMeans merupakan metode yang simple dan cepat perhitungannya [3].

Berdasarkan dari semua latar belakang yang telah dibahas sebelumnya, maka penulis tertarik untuk mencoba membuat suatu system untuk mengidentifikasi daun dengan menggunakan metode K-Means clustering.

\section{Metode Penelitian}

Alur analisis penelitian dilakukan berdasarkan permasalahan yang telah di jabarkan dalam pendahuluan dan akan ditangani oleh sistem, dimana 
sistematika penelitian yang digunakan pada penelitian ini sebagai berikut:

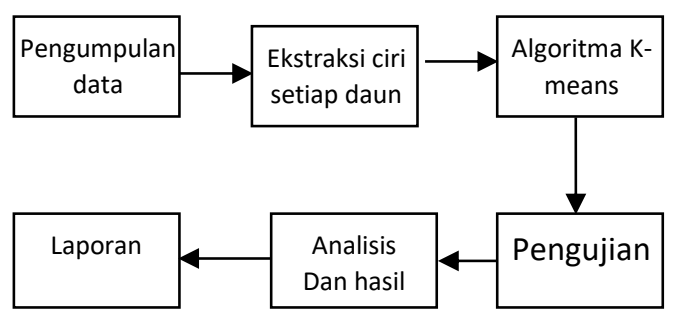

Gambar 2.1 Sistematika Penelitian

\subsection{Metode Pengumpulan Data}

Data penelitian dapat dikelompokkan menjadi dua jenis yaitu data primer dan data sekunder. Pemahaman terhadap kedua jenis data tersebut diperlukan sebagai landasan dalam menentukan teknik serta langkahlangkah pengumpulan data penelitian.

1. Data Primer atau data asli yang dikumpulkan secara langsung dari sumber datanya atau diperoleh dari sumber langsung. Untuk mendapatkan data primer, peneliti harus mengumpulkannya secara langsung. Teknik yang dapat digunakan peneliti untuk mengumpulkan data primer antara lain observasi, wawancara, diskusi terfokus.

2. Data Sekunder data yang diperoleh atau dikumpulkan peneliti dari berbagai sumber yang telah ada.Data sekunder dapat diperoleh dari berbagai sumber seperti buku, jurnal, skripsi dan tesis.

\subsection{Dataset dan Data Tes}

Dataset yang digunakan dalam kasus ini adalah berupa citra atau image, baik citra berwarna maupun citra grayscale. Dalam penelitian ini citra yang diujikan adalah citra berwarna. Ada 5 buah citra yang disediakan antara lain
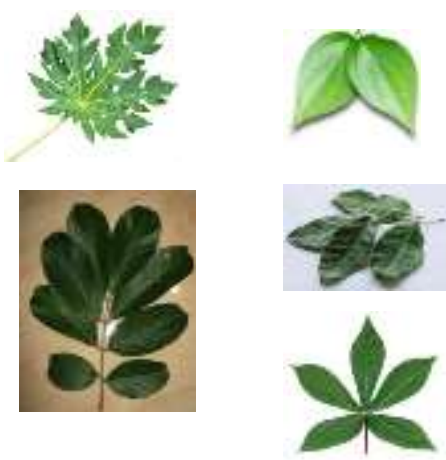

\section{Gambar 2.2 Dataset segmentasi Citra berupa daun}

Masing-masing dari dataset diatas dilakukan ekstraksi ciri-ciri meliputi analisis bentuk dan tekstur dengan menggunakan Metode GLCM ( Gray Level Co-Occurrence Matrix). Hasil ekstraksi ciri tersebut sebagai pembanding hasil segmentasi dengan menggunakan metode K-Means
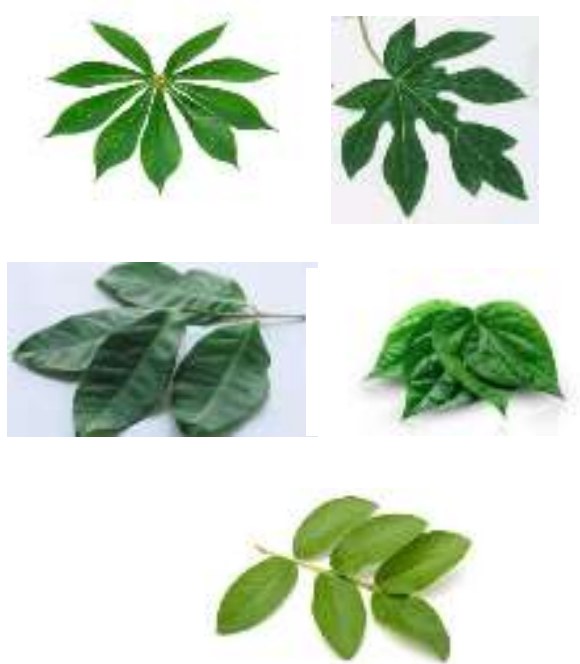

Gambar 2.3 Data Uji Segmentasi Citra berupa daun 
Masing-masing Data uji akan dilakukan identifikasi apakah data uji sesuai dengan hasil yang diharapkan

\subsection{Segmentasi Citra}

Segmentasi merupakan teknik untuk membagi suatu citra menjadi beberapa wilayah (region) dimana setiap wilayah memiliki kemiripan atribut [6].Pengolahan citra digital merupakan sebuah disiplin ilmu yang mempelajari hal-hal yang berkaitan dengan perbaikan kualitas gambar (peningkatan kontras, transformasi warna, restorasi citra), transformasi gambar (rotasi, translasi, skala, transformasi geometrik), melakukan pemilihan citra ciri (feature images) yang optimal untuk tujuan analisis, melakukan proses penarikan informasi atau deskripsi objek atau pengenalan objek yang terkandung pada citra,melakukan kompresi atau reduksi data untuk tujuan penyimpanan data, transmisidata, dan waktu proses data. Input dari pengolahan citra adalah citra, sedangkan output-nya adalah citra hasil pengolahan.

Metode segmentasi citra dikelompokkan menjadi dua bagian, yaitu metode segmentasi low level dan high level. Metode segmentasi low level misalnya mean shift,watershed, level set, dan super pixel biasanya membagi gambar menjadi beberapa daerah kecil. Meskipun hasil segmentasinya sering over segmentation, namun metode segmentasi low level memberikan dasar yang bagus untuk operasi segmentasi high level selanjutnya. Metode segmentasi high level misalnya region merging, graph cut [7].

\subsection{Segmentasi Citra Berbasis Clustering}

Segmentasi citra berbasis clustering menggunakan data multi dimensi untuk mengelompokkan piksel citra ke dalam beberapa clustering. Data multidimensi pada citra ini maksudnya adalah banyaknya atribut atau komponen penyusun suatu citra, misalnya citra grayscale mempunyai satu buah dimensi,citra RGB mempunyai tiga buah dimensi, dan sebagainya. Pada umumnya pikseldi-clustering berdasarkan kedekatan jarak antar piksel. Segmentasi berbasis clustering ini mulai populer sejak diimplementasikan pada aplikasi OCR (OpticalCharacter Recognition), pengenalan sidik jari hingga remote sensing. Keberhasilan dari proses segmentasi berbasis clustering ini ditentukan dari keberhasilan dalam mengelompokkan fitur-fitur yang berdekatan ke dalam satu cluster [6].

Metode-metode dalam segmentasi berbasis clustering di antaranya adalah metode iterasi, K-Means, Fuzzy Cmeans, jaringan syaraf Kohonen, dan berbagai teknik cluster lainnya. Salah satu metode yang sangat baik digunakan untuk segmentasi citra adalah Fuzzy CMeans clustering. Fuzzy C-Means ini merupakan algoritma K-means yang diimprovisasi dengan Fuzzy Set Theory dengan menerapkan derajat keanggotaan, dimana satu piksel citra dapat dimiliki olehbeberapa cluster. "Soft" clustering ini memberikan komputasi yang lebih tepatdalam menentukan keanggotaan dari cluster.

\subsection{K-means}

Algoritma K-means merupakan salah satu algoritma dengan partitional, karena K-Means didasarkan pada penentuan jumlah awal kelompok dengan mendefinisikan nilai centroid awalnya [9]. Algoritma K -means menggunakan proses secara berulang-ulang. untuk mendapatkan basis data cluster. Dibutuhkan jumlah cluster awal yang diinginkan sebagai masukan dan menghasilkan titik centroid akhir sebagai output. Metode K-means akan memilih pola $\mathrm{k}$ sebagai titik awal centroid secara 
acak atau random. Jumlah iterasi untuk mencapai cluster centroid akan dipengaruhi oleh calon cluster centroid awal secara random. Sehingga didapat cara dalam pengembangan algoritma dengan menentukan centroid cluster yang dilihat dari kepadatan data awal yang tinggi agar mendapatkan kinerja yang lebih tinggi [10].

\subsection{Ekstraksi Ciri}

Ekstraksi ciri merupakan salah satu tahapan dalam sistem CBIR yang berguna untuk mendapatkan karakteristik visual citra [11]. Ekstraksi ciri adalah proses mengambil ciri-ciri yang terdapat pada citra. Ciri-ciri tersebut adalah besaran komponen tertentu dari citra objek yang mewakilisifat utama citra objek, sekaligus mengurangi dimensi citra objek menjadi sekumpulan bilangan yang lebih sedikit tetapi representative [12].

Tujuan utama dari proses ekstraksi ciri adalah untuk mengkarakterisasi objek yang ingin dikenali dari sebuah citra dengan menggunakan ukuranukuranyang memiliki nilai sangat mirip untuk objek pada kategori yang sama dan sangatberbeda untuk objek pada kategori yang tidak sama.

Tabel 2.1 Formula Ektraksi Ciri Analisis Bentuk

\begin{tabular}{|c|c|c|}
\hline No & Feature & Formula \\
\hline $\mathbf{1}$ & Metric & $M=\frac{4 \pi \times A}{c^{2}}$ \\
\hline $\mathbf{2}$ & Eccentricity & $e=\sqrt{1-\frac{b^{2}}{a^{2}}}$ \\
\hline
\end{tabular}

\subsection{Metode GLCM ( Gray Level Co-}

\section{Occurrence Matrix)}

Metode GLCM merupakan suatu metode yang melakukan analisis terhadap suatu piksel pada citra dan mengetahui tingkat keabuan yang sering terjadi [11]. Metode ini juga untuk tabulasi tentang frekuensi kombinasi nilai piksel yang muncul pada suatu citra. Untuk melakukan analisis citra berdasarkan distribusi statistik dari intensitas pikselnya, dapat dilakukan dengan mengekstrak fitur teksturnya. GLCM merupakan suatu metode untuk melakukan ekstraksi ciri berbasis statistikal, perolehan ciri diperoleh dari nilai piksel matrik, yang mempunyai nilai tertentu dan membentuk suatu sudut pola [13].

Berdasarkan kondisi tersebut terlihat bahwa untuk membedakan antar matrik gambar dapat dilihat berdasarkan ciri matrik dengan menggunakan persamaan sebagai berikut;

Tabel 2.2Formula Ekstraksi Ciri Analisis Tekstur

\begin{tabular}{|l|l|l|}
\hline $\mathrm{N}$ & Feature & \multicolumn{1}{|c|}{ Formula } \\
$\mathrm{o}$ & & \\
\hline 1 & Contras & $\underline{\sum_{i} \sum_{j}(i-j)^{2} C(i, j)}$ \\
\hline 2 & Energy & $\underline{\sum_{i} \sum_{j} C^{2}(i, j)}$ \\
\hline 3 & $\begin{array}{l}\text { Correlati } \\
\text { on }\end{array}$ & $\frac{\sum_{i} \sum_{j} C(i, j) \log (C(i, j)}{}$ \\
\hline 4 & $\begin{array}{l}\text { Homoge } \\
\text { nitas }\end{array}$ & $\frac{\sum_{i} \sum_{j} \frac{C(i, j)}{1+|i+j|}}{}$ \\
\hline
\end{tabular}

\section{Hasil dan Pembahasan}

\subsection{Antarmuka Sistem}

Antarmuka sistem ini berfungsi untuk mempermudah pengoperasian aplikasi segmentasi citra dengan metode K-means clustering 


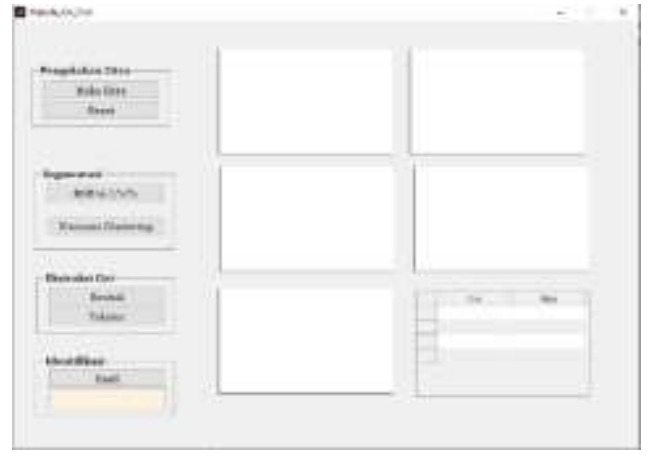

Gambar 3.1 Antarmuka Sistem Segmentasi Citra

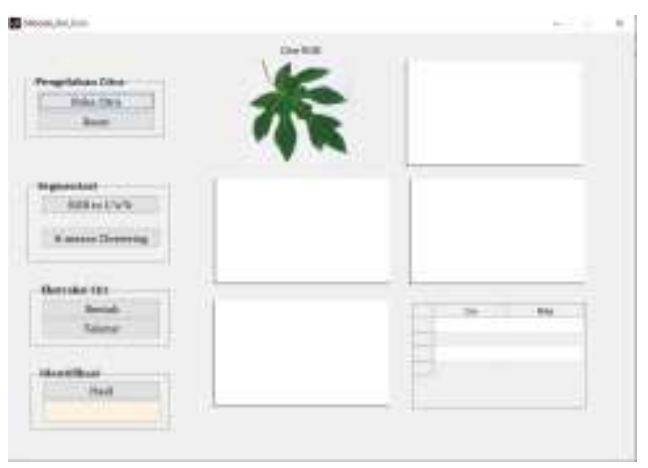

Gambar 3.2. Antarmuka Input Sistem

Segmentasi Citra

Citra uji ditampilkan pada panelutama yang selanjutnya dapat diproses menggunakan metode K-means clustering

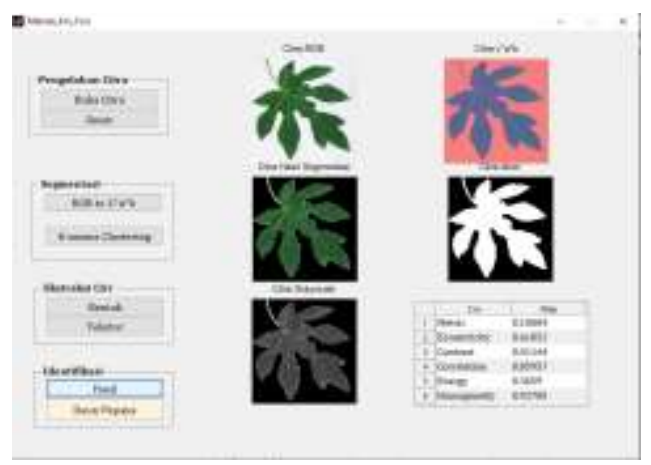

Gambar 3.3 Antarmuka Proses segmentasi citra

Pada Antarmuka gambar di atas, ditampilkan informasi analisis bentuk yaitu nilai metric dan eccentricity, analisis tekstur yaitu nilai contras, correlation, energy dan homogenity.
Setelah proses analisis bentuk dan analisis tekstur selesai proses selanjutnya adalah menentukan identifikasi hasil pengenalan pola menggunakan segmentasi K-Means clustering.

\subsection{Hasil Identifikasi Citra daun dengan menggunakan metode $\mathrm{K}$ - Means}

Hasil uji coba citra uji daun menggunakan metode K-Means ditampilkan pada gambar dibawah ini

\subsubsection{Hasil Uji Daun pepaya menggunakan metode K-Means clustering}

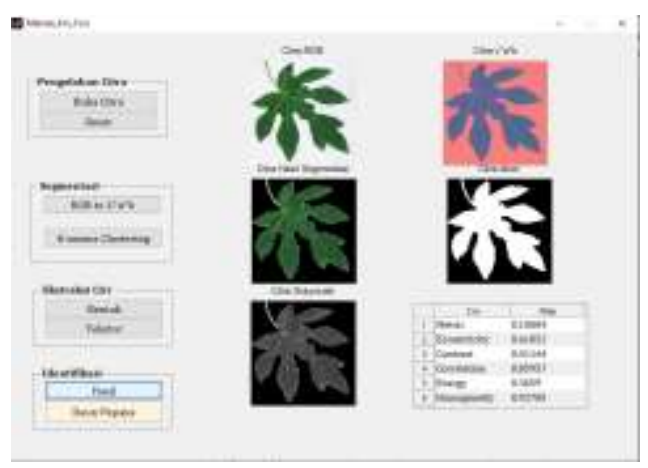

Gambar 3.4 Hasil uji daun pepaya menggunakan K-Means

\subsection{Hasil Analisa Tekstur dan Analisa Bentuk}

Perbandingan Analisis Bentuk meliputi metric dan eccentricity sedangkan Analisis Tekstur meliputi contras, correlation, energy dan homogeneity. Hasil perbandingan analisis ini dapat dilihat pada tabel dibawah ini.

Tabel 3.3 Perbandingan Analisis Bentuk dan Analisis Tekstur KMeans clustering 


\begin{tabular}{|c|c|c|c|}
\hline Citra Uji & Metode & Metric & $\begin{array}{c}\text { Eccentrici } \\
\text { ty }\end{array}$ \\
\hline \multirow{2}{*}{$\begin{array}{l}\text { Daun } \\
\text { Pepaya }\end{array}$} & $\mathrm{KM}$ & $\begin{array}{c}0.1000 \\
4\end{array}$ & 0.41052 \\
\hline & Citra & 0.0765 & 0.5042 \\
\hline \multirow{2}{*}{$\begin{array}{c}\text { Daun } \\
\text { Rambuta } \\
\text { n }\end{array}$} & KM & 0.2439 & 0.78136 \\
\hline & Citra & 0.4226 & 0.7041 \\
\hline \multirow{2}{*}{$\begin{array}{l}\text { Daun } \\
\text { Salam }\end{array}$} & $\mathrm{KM}$ & 0.2702 & 0.89829 \\
\hline & Citra & 0.1301 & 0.4339 \\
\hline \multirow{2}{*}{$\begin{array}{c}\text { Daun } \\
\text { Singkong }\end{array}$} & KM & $\begin{array}{c}0.0694 \\
4 \\
\end{array}$ & 0.73525 \\
\hline & Citra & 0.8118 & 0.6006 \\
\hline \multirow{2}{*}{$\begin{array}{l}\text { Daun } \\
\text { Sirih }\end{array}$} & KM & 0.36688 & 0.80839 \\
\hline & Citra & 0.4887 & 0.7424 \\
\hline
\end{tabular}

\begin{tabular}{|c|c|c|c|}
\hline \multirow{2}{*}{$\begin{array}{c}\text { Daun } \\
\text { Singkong }\end{array}$} & KM & 0.25152 & 0.91931 \\
\cline { 2 - 4 } & Citra & 0.1623 & 0.9708 \\
\hline $\begin{array}{c}\text { Daun } \\
\text { Sirih }\end{array}$ & KM & 0.315 & 0.92087 \\
\cline { 2 - 4 } & Citra & 0.3354 & 0.9725 \\
\hline
\end{tabular}

\begin{tabular}{|c|c|c|c|}
\hline Citra Uji & Metode & Energy & $\begin{array}{c}\text { Homoge } \\
\text { nity }\end{array}$ \\
\hline $\begin{array}{c}\text { Daun } \\
\text { Pepaya }\end{array}$ & KM & 0.3659 & 0.92705 \\
\cline { 2 - 4 } & Citra & 0.3869 & 0.9188 \\
\hline \multirow{2}{*}{$\begin{array}{c}\text { Daun } \\
\text { Rambuta }\end{array}$} & KM & 0.36049 & 0.95438 \\
\cline { 2 - 4 } & Citra & 0.3013 & 0.9549 \\
\hline \multirow{2}{*}{$\begin{array}{c}\text { Daun } \\
\text { Salam }\end{array}$} & KM & 0.44172 & 0.99145 \\
\cline { 2 - 4 } & Citra & 0.4577 & 0.9584 \\
\hline \multirow{2}{*}{$\begin{array}{c}\text { Daun } \\
\text { Singkong }\end{array}$} & KM & 0.56974 & 0.96113 \\
\cline { 2 - 4 } $\begin{array}{c}\text { Sirih } \\
\text { Daun }\end{array}$ & KM & 0.48972 & 0.92886 \\
\cline { 2 - 4 } & Citra & 0.2758 & 0.9524 \\
\hline
\end{tabular}

\begin{tabular}{|c|c|c|c|}
\hline Citra Uji & Metode & Contras & $\begin{array}{c}\text { Correlati } \\
\text { on }\end{array}$ \\
\hline $\begin{array}{c}\text { Daun } \\
\text { Pepaya }\end{array}$ & $\mathrm{KM}$ & 0.41144 & 0.85957 \\
\cline { 2 - 4 } & Citra & 0.5310 & 0.9332 \\
\hline $\begin{array}{c}\text { Daun } \\
\text { Rambuta } \\
\mathrm{n}\end{array}$ & $\mathrm{KM}$ & 0.27372 & 0.96111 \\
\cline { 2 - 4 } & Citra & 0.1446 & 0.9725 \\
\hline \multirow{2}{*}{$\begin{array}{c}\text { Daun } \\
\text { Salam }\end{array}$} & KM & 0.11537 & 0.99496 \\
\cline { 2 - 4 } & Citra & 0.2238 & 0.9282 \\
\hline
\end{tabular}




\subsection{Hasil Analisa Identifikasi}

Hasil identifikasi dari segmentasi citra daun menggunakan metode $\mathrm{K}$ Means clustering ditampilkan pada pada tabel 3.4 dibawah ini.

Tabel 3.4 Perbandingan Hasil Identifikasi

\begin{tabular}{|l|l|l|c|}
\hline Citra Uji & $\begin{array}{c}\text { Metod } \\
\text { e }\end{array}$ & $\begin{array}{c}\text { Identifikas } \\
\text { i }\end{array}$ & $\begin{array}{c}\text { Ket } \\
\text { • }\end{array}$ \\
\hline $\begin{array}{l}\text { Daun } \\
\text { Pepaya }\end{array}$ & KM & $\begin{array}{l}\text { Daun } \\
\text { Pepaya }\end{array}$ & $\sqrt{ }$ \\
\hline $\begin{array}{l}\text { Daun } \\
\text { Rambuta } \\
\text { n }\end{array}$ & KM & $\begin{array}{l}\text { Daun } \\
\text { Salam }\end{array}$ & X \\
\hline $\begin{array}{l}\text { Daun } \\
\text { Salam }\end{array}$ & KM & $\begin{array}{l}\text { Daun } \\
\text { Salam }\end{array}$ & $\sqrt{ }$ \\
\hline $\begin{array}{l}\text { Daun } \\
\text { Singkong }\end{array}$ & KM & $\begin{array}{l}\text { Daun } \\
\text { Singkong }\end{array}$ & $\sqrt{ }$ \\
\hline $\begin{array}{l}\text { Daun } \\
\text { Sirih }\end{array}$ & KM & Daun Sirih & $\sqrt{ }$ \\
\hline
\end{tabular}

Berdasarkan tabel hasil identifikasi dapat dilihat bahwa hasil identifikasi dengan metode K-Means clustering menghasilkan identifikasi yang cukup akurat. Walaupun terdapat kesalahan identifikasi pada daun rambutan yang di identifikasi sebagai daun salam.

\section{Simpulan}

Berdasarkan 5 kali uji coba yang telah dilakukan dalam penelitian ini dapat disimpulkan bahwa dalam segmentasi untuk identifikasi pola menggunakan analisis tekstur dan analisis bentuk, hasil identifikasi daun dengan metode K-Means clustering dapat dilakukan dari 5 kali percobaan terdapat satu kesalahan identifikasi yaitu pada daun rambutan yang di identifikasi sebagai daun salam.

\section{Daftar Pustaka}

[1] Gunawan, F Alim. \&Erni W.,2011.Perangkat Lunak Segmentasi Citra Dengan Metode Watershed. JSIFO STMIK Mikroskil.Vol.12-No.2, Pp.79-88.
[2] Amiya Halder, Soumajit Pramanik. 2011. Dynamic Image Segmentation Using Fuzzy C-Means Based Genetic Algorithm. International Journal Of Computer Application, Vol. 28-No.6,Pp.15-20

[3] Arthur, D. danVassilvitskii, S. 2006. How Slow is the k-Means Method, Stanford University, Stanford, CA.

[4] Rasmana. Susijanti Tri,.2013.Peningkatan Kualitas Citra Prasasti Logam Berbasis Klasifikasi Fitur Warna Menggunakan Support Vector Machine, Proposal Desertasi Istitut Teknologi Sepuluh Nopember Surabaya.

[5] Gernot Hoffmann, CIE Color Space, 2010.

[6] Darma Putra. 2010. Pengolahan Citra Digital. Yogyakarta : ANDI Offset

[7] Ning, J., Zhang, D., Wu, Chengke. 2009. Interactive Image Segmentation by Maximal Similarity Based Region Merging, pp. 445456.

[9] Madhulatha, T.S., 2012. An Overview On Clustering Methods. Iosr Journal Of Engineering, Ii(1), Pp.719-725.

[10] B. Sowmya, B. Sheela Rani. 2010. Colour image segmentation using fuzzy clustering techniques and competitive neural network, Elsevier Applied Soft Computing ScienceDirect. Sathyabama University, Old Mamallapuram Road, Chennai 600119, India

[11]Herdiyeni, Y dan Widyanto, M. R. 2007. Sistem Temu Kembali Citra DenganUkuranKemiripan Warna Dalam Ruang RGB Berbasis Sistem Inferensi Fuzzy. Proceedings of National Conference on Computer Science andInformation Technology. Fakultas IlmuKomputer. UniversitasIndonesia.Jakarta 
[12] Syahputra, H. 2009. Ekstraksi Fitur Menggunakan Elliptical Fourier DescriptoruntukPengenalan Varietas Tanaman Kedelai. Institut Pertanian Bogor.Bogor

[13] Xie, Q., Huang ,D., Zhang,S.,Dan Cao,J., (2010), Analysis Of A Viral Infection Model With Delayed Immune Response, Applied Mathematical Modelling , 34, Hal.2388-2395 